The Journal of Animal \& Plant Sciences, 30(5): 2020, Page: 1236-1245

ISSN (print): 1018-7081; ISSN (online): 2309-8694

\title{
PHARMACOGNOSTIC AND PHYTOCHEMICAL SCREENING OF COCCULUS PENDULUS Diels. STEM AND ROOT
}

\author{
M. Nafees ${ }^{1 *}$, S. Ullah ${ }^{1}$, Barkatullah ${ }^{2}$, A. Javaid ${ }^{1}$ and Shumaila ${ }^{1}$ \\ ${ }^{1}$ Department of Botany, University of Peshawar, 25120, Pakistan; ${ }^{2}$ Department of Botany, Islamia College University, \\ Peshawar, 25120, Pakistan \\ *Corresponding Author’s E-mail: nafeesbotanist1990@gmail.com
}

\begin{abstract}
Cocculus pendulus Diels. belongs to family Menispermaceae locally known as "Parwatti" is a part of medicines against jaundice, yellow fever, leprosy, syphilis and as an aphrodisiac. To authenticate the $C$. pendulus from adulterations, in the present study the stem and root has been evaluated for different pharmacognostic studies. Morphologically the plant is dioecious, woody climber (Liana) and about $4-8 \mathrm{~m}$ tall. The macroscopic study showed that stem is cylindrical in shape, characteristic odor, acceptable taste and brittle fracture while the root is irregular in shape with characteristic odor and bitter taste. Histologically both plant parts showed typical dicot anatomy. Preliminary phytochemical screening showed the presence of proteins, carbohydrates, alkaloids, tannins, saponins, steroids, flavonoids, glycosides and phenolic compounds in both plant parts. Quantitatively highest amount of sterols $85.32 \pm 2.42 \mathrm{mg} / \mathrm{g}$ followed by alkaloids $30.45 \pm 0.32 \mathrm{mg} / \mathrm{g}$ in root while stem with $71.43 \pm 1.24 \mathrm{mg} / \mathrm{g}$ amount of sterols and $21.47 \pm 0.54 \mathrm{mg} / \mathrm{g}$ alkaloids has been recorded. Fluorescence analysis showed diverse colors by treating with different reagents at ordinary and UV light. Powdered drug study and percent extractive values determination were also carried out. Pharmacognostic studies will be helpful in the standardization and authentication of the species from adulteration as the above studies has been carried out for the first time for the said plant.
\end{abstract}

Key words: Cocculus pendulus, fluorescence analysis, pharmacognosy, phytochemical screening.

https://doi.org/10.36899/JAPS.2020.5.0141

Published online June 25, 2020

\section{INTRODUCTION}

Plants have always been the principal source of medicine in the world. Several drugs has been derived from plant sources that are being used today (Rao et al. 2010). It is thought that in developing countries $80 \%$ of the people are dependent on traditional medicines for their primary healthcare (Kim et al. 2001). About $80 \%$ compounds has been derived from 94 species of plants, which are being used for ethnomedical purposes (Kokate et al. 2008). So, the present study has been carried out to explore Cocculus pendulus which may be helpful for the treatments of many ailments.

Cocculus pendulus Diels. Synonym: Cocculus leaeba DC. belongs to family Menispermaceae locally known as "Parwatti (Fig.1). It is a dioecious, shrubby plant with $15 \mathrm{~cm}$ diameter of the stem at the base. Leaves are broad, oblong lanceolate, with obtuse apex, generally glabrous or puberulous. Fruit composed of 1-3 flattened drupes. Seed horse-shoe shaped, laterally flattened (Rabari et al. 2010). People in Pakistan and Afghanistan use the plant parts, especially the roots to cure fevers, including intermittent fever. In Nigeria the root and leaves are used for this purpose while in Senegal the Toucouleur and Paul people use both root and stem bark for the same purpose. In Senegal the Toucouleur and Paul people use root and stem bark decoctions against intestinal parasites and gonorrhea (Rabari et al. 2011). The root has a great reputation in Senegal against biliousness and menstrual problems and as a diuretic. It is also a part of medicines against jaundice, yellow fever, leprosy, syphilis and as an aphrodisiac in the area (Rabari et al. 2010). The literature studies also showed that $C$. pendulus stem and root has not been analyzed for pharmacognostic work. So, in the present studies stem and root has been investigated for pharmacognostic profile.

\section{MATERIALS AND METHODS}

Specimen collection and preservation: The fresh stem and root of the experimental plant were collected in January 2015 from the Tribal area, Sama Bada Bera, Labi Khel, F.R Peshawar located at $33.8078^{\circ}$ North latitude and $71.7356^{\circ}$ East longitude and elevation of the area above the sea level is $1,000 \mathrm{~m}$. This area comes under subtropical zone. The relative humidity varies from $46 \%$ in June to $76 \%$ in August. Specimens were identified by Dr. Barkatullah, Lecturer, Department of Botany, University of Peshawar mounted on Herbarium sheet and provided with a Voucher number Bot-UOP-2015, and deposited in the herbarium. Both stem and root were completely dried under the sun and grinded by electric grinder. After grinding the powdered drugs were kept in 
impermeable bottles and were used for different pharmacognostic studies.

\section{Pharmacognostic evaluation}

Morphology and Macroscopy: Morphological and macroscopic features of the stem and root were conducted by organoleptic method following the methodology of Evans (2002); Wallis (2009). Both plant parts were studied for color, shape, inner surface, outer surface, fracture, taste and odor.

Microscopic evaluation: The microscopic and histological features of the leaf were carried out by hand sectioning using the standard procedure of Chaffey (2001); Evans (2002); Wallis (2009). Sharp razor were used for making thin fine transverse sections of the stem and root. Fine sections were selected, stained properly and observed under Digital Labomed microscope (Model iVu 3100 and no. Lx 400).

Preparation of extract: $250 \mathrm{~g}$ dried powder of stem and root separately were treated with 1 liter ethanol and shake at regular intervals for 48 hours. After 48 hours the extract was filtered, the filtrate were collected and processed in rotary to make the final volume $1 / 5$ of the original volume and stored in impermeable glass bottles at $4^{\circ} \mathrm{C}$ for further evaluation Evans (2002).

Qualitative Phytochemical evaluation: For the determination of different phytoconstituents like alkaloids, fats, phytosterols, fixed oils, glycosides, proteins, flavonoids, saponins and tannins, various phytochemical tests of the ethanolic extract were carried out.

\section{Carbohydrate detection test}

$>\quad$ Molisch's test: Few drops of Molish reagent were added to $1 \mathrm{ml}$ extract solution. Through the side of the test tube concentrated sulphuric acid were added. Purple to violet color ring appearance at the junction will be the detection of carbohydrates Evans (2002).

$>\quad$ Benedict test: The addition of Benedict reagent to $1 \mathrm{ml}$ extract solution followed by placing on water bath and the appearance of reddish brown precipitate appearance will be the indication of reducing sugar otherwise absent Evans (2002).

\section{Proteins and amino acids detection test}

$>\quad$ Biuret test: The addition of equal volumes of $\mathrm{NaOH}(5 \%)$ and $\mathrm{CuSo} 4(1 \%)$ to $1 \mathrm{ml}$ extract solution and the appearance of violet color will be the indication for the presence of free amino acids and proteins otherwise absent Kumar and Kiladi (2009).

$>\quad$ Ninhydrin test: Boiling of crude extract at $100^{\circ} \mathrm{C}$ with $1 \mathrm{ml}$ Ninhydrin solution and appearance of violet color will be the indication for the presence of amino acids and proteins otherwise absent Kumar and Kiladi (2009).

$>\quad$ Xanthoproteic test: The addition of few drops of concentrated of $\mathrm{HNO} 3$ to $2 \mathrm{ml}$ extract solution made in distilled water and the appearance of cloud upon heating changing to yellow which turns to an orange color by adding ammonia will indicate of the presence of amino acids otherwise absent Kokate et al. (2008).

\section{Alkaloid detection tests}

$>\quad$ Dragondorff's test: Add 2-3ml Dragondorff's reagent to $1 \mathrm{ml}$ extract solution. If orange brown precipitate appears it will indicate the presence of alkaloids Khandelwal (2004).

$>\quad$ Wagner's test: The addition of Wagner's reagent to $1 \mathrm{ml}$ extract solution and the formation of reddish brown precipitate will be the indication of the presence of alkaloids otherwise absent Khandelwal (2004).

$>\quad$ Hager's test: The addition of Hager's reagent to $1 \mathrm{ml}$ extract solution followed by the formation of yellow precipitate will be the indication of the presence of alkaloids otherwise absent Khandelwal (2004).

\section{Triterpenoids and Phytosterols detection}

$>\quad$ Salkowski's test: The addition of $0.5 \mathrm{ml}$ concentrated $\mathrm{H}_{2} \mathrm{SO}_{4}$ to $1 \mathrm{ml}$ extract solution made in chloroform through the side of test tube and the appearance of red color at lower layer will indicate the presence of sterol, while yellow color appearance will be the indication of triterpenoids presence Harnborne (1998).

\section{Phenol detection test}

$>\quad$ Ferric chloride test: The addition of $1 \mathrm{ml} \mathrm{FeCl}_{3}$ solution to $1 \mathrm{ml}$ extract solution and the appearance of bluish green color appearance will be the indication for the presence of total phenols otherwise absent Dahiru et al. (2006).

\section{Test for Flavonoids}

$>\quad$ Alkali reagent test: The addition of $\mathrm{NaOH}$ to 1 $\mathrm{ml}$ extract solution and the appearance of yellow to red color precipitation will indicate for the presence of flavonoids otherwise absent Kokate et al. (2008).

\section{Test for the Tannins}

$>\quad$ Ferric chloride test: The addition of $1 \mathrm{ml} \mathrm{5 \%}$ $\mathrm{FeCl}_{3}$ to $1 \mathrm{ml}$ extract solution followed by appearance of greenish black color will indicate the presence of tannins otherwise absent Wallis (2009).

$>\quad$ Alkali reagent test: The addition of Sodium hydroxide to $1 \mathrm{ml}$ extract solution and the formation of 
yellow red precipitate will indicate the presence of tannins otherwise absent Wallis (2009).

\section{Saponins detection test}

$>\quad$ Frothing test: The formation of persistent froth by vigorous shaking of extract in distilled water will be the indication of saponins prescence Evans (2002).

\section{Steroidal glycosides detection test}

$>\quad$ Killaer Kilani test: The addition of glacial acetic acid to $1 \mathrm{ml}$ extract solution and addition of one drop of concentrated $\mathrm{H}_{2} \mathrm{SO}_{4}$ through the side of test tube and formation of reddish brown color precipitate at the junction will be the indication of glycosides presence Harnborne (1998).

\section{Fixed oils presence test}

$>\quad$ Spot test: The rubbing of extract between two filter papers and the existence of permanent spot will be the indication of fixed oil presence Kumar and Kiladi (2009).

Volatile oil: The rubbing of a small amount extract between two filter papers and the absence of permanent stain will be the indication of volatile oil presence Kumar and Kiladi (2009).

\section{Quantitative phytochemical screening}

Alkaloids determination: The methodology of Wallis (2009) was adopted for the quantitative screening of total alkaloids. $100 \mathrm{ml}$ acetic acid $(10 \%)$ was taken in which $2 \mathrm{~g}$ crude ethanolic extract of stem and root were dissolved. The solution was allowed to stand for 4 hours and then filtered. After filtration, the extracts were placed on a water bath for further concentration to reduce the volume to one-fourth. Precipitate formation occurred by the addition of Concentrated $\mathrm{NH} 4 \mathrm{OH}$ drop wise. Dilute $\mathrm{NH} 4 \mathrm{OH}$ was used for washing the collected precipitate. The obtained product was collected and weighted using the following formula.

Amount of alkaloid $(\mathrm{mg} / \mathrm{g})=\frac{\mathrm{w} 2-\mathrm{w} 1}{\text { Weight of sample }}$

$\mathrm{W}_{1}=$ Weight of filter paper $\mathrm{W}_{2}=$ Weight of filter paper + ppt

Saponins determination: The methodology of Obadoni and Ochuko (2001) was adopted to carry out the detection of total saponins contents quantitatively. $20 \mathrm{ml}$ distilled water were taken in which $2 \mathrm{~g}$ crude ethanolic extract of stem and root were dissolved and transferred into a separating funnel. $20 \mathrm{ml}$ diethyl ether were added and shake well. The ether layer was discarded and the aqueous layer was separated. $60 \mathrm{ml} \mathrm{n}$-Butanol was added for the purification of the product followed by washing the extract twice by $10 \mathrm{ml} 5 \%$ aqueous $\mathrm{NaCl}$. The product obtained were boiled on water bath and dried.
The saponins content were calculated using the following formula.

$$
\begin{gathered}
\text { Amount of saponins }(\mathrm{mg} / \mathrm{g})=\frac{\mathrm{w} 2-\mathrm{w} 1}{\text { Weight of sample }} \\
\mathrm{W}_{2}=\text { Weight of filter paper }+ \text { residue } \\
\mathrm{W}_{1}=\text { Weight of filter paper }
\end{gathered}
$$

Sterol determination: The methodology of Huang et al. (2010) was adopted to carry out the detection of total sterols contents quantitatively. $75 \mathrm{ml}$ distilled water were taken to which $2 \mathrm{~g}$ crude ethanolic extract of stem and root were added. $25 \mathrm{ml}$ potassium hydroxide $(10 \%)$ was added to the solution. This mixture was then poured into a separating funnel followed by the addition of $75 \mathrm{ml}$ petroleum ether thrice for extraction. The ether fraction was separated from the funnel and transferred into a flask which was pre weighted $\left(\mathrm{W}_{1}\right)$. The extract were boiled on hot water bath followed by drying and cooling. The flask was again weighted $\left(\mathrm{W}_{2}\right)$ and total sterol contents were obtained using the following formula.

Amount of sterol $(\mathrm{mg} / \mathrm{g})=\frac{\mathrm{w} 2-\mathrm{w} 1}{\text { Weight of sample }}$
$\mathrm{W}_{2}=$ Weight of flask + residue
Weight of flask

Tannins determination: The methodology of VanBuren and Robinson (1969) was carried out for the quantitative determination of tannins. $75 \mathrm{ml}$ distilled water were taken in which $2 \mathrm{~g}$ crude ethanolic extract were dissolved. The suspension was then filtered. Lead acetate saturated solution were added to the filtrate in order to get lead-tinnate precipitate. $20 \mathrm{ml}$ distilled water was added followed by treating with dilute $\mathrm{H} 2 \mathrm{SO} 4$, which acidified the solution. Then the mixture was filtered through the pre-weighted Whatman filter paper (W1) to get the tannins. The filter paper was then dried. By weighting the filter paper the amount of tannins were calculated.

$$
\begin{aligned}
& \text { Amount of tannins }(\mathrm{mg} / \mathrm{g})=\frac{\mathrm{w} 2-\mathrm{w} 1}{\text { Weight of sample }} \\
& \mathrm{W}_{2}=\text { Weight of filter paper }+ \text { residue } \quad \mathrm{W}_{1}=\text { Weight } \\
& \text { of filter paper }
\end{aligned}
$$

Powdered drug study: Both the plant parts were sun dried at for 10 days and grinded with the help of electric grinder. A little amount of fine powder drug were treated with chloral hydrate solution, iodine solution and glycerin and observed under Labomed microscope for different histological structures following Wallis (2009).

Fluorescence analysis: The fluorescence screening of the powdered drugs of the both plant parts were carried out by treating a little amount of powder with different reagents like methanol, $\mathrm{NaOH}$ in water, diethyl ether, iodine solution, $\mathrm{HNO}_{3}, \mathrm{H}_{2} \mathrm{SO}_{4}, \mathrm{FeCl}_{3}$ solution and $\mathrm{NH}_{3}$ solution. All these treated powdered were examined under UV light and ordinary day light (UV 254 and UV 336) Nikam et al. (2009); Wallis (2009). 
Extractive values analysis: The methodology of Ansari et al. (2006) has been followed for the determination of extractive values of stem and root powdered drug. 15 gram powdered drug was soaked in $250 \mathrm{ml}$ each solvent (ethanol, n-Hexane, methanol, chloroform, acetone and phenyl ether) separately and kept for 8 days in air tight bottles with regular shaking every day. Each fraction was filtered after 8 days and the filtrate was dried. Following formula was used for the extractive values determination: Percent $(\%)$ extractive value $(\mathrm{w} / \mathrm{w})=\frac{\text { weight of the extract }}{\text { weight of the sample }} \times$ 100

\section{RESULTS}

Morphological and macroscopic features: Cocculus pendulus is a woody climber (Liana) about $4-8 \mathrm{~m}$ tall. In the present study the stem and root of C. pendulus were evaluated for its morphological features. The macroscopic study revealed that the stem is cylindrical in shape, outer surface light brown, inner surface light yellow, odor characteristic, acceptable taste and has brittle fracture while the root is irregular in shape, outer surface light brown, inner surface light yellow, odor characteristic with slightly bitter taste and brittle fracture (Table. 1). Upadhyay et al. (2010); Akbar et al. (2014) worked out on Euphorbia hirta and Malva parviflora respectively and said that organoleptic evaluation is the primary technique for the correct identification of a plant by sense organs and provide a base for the crude drug authentication from adulteration.

Microscopic evaluation: Histological evaluation is the most important method use for the authentication of a crude drug. Transverse section of $C$. pendulus stem showed that Epidermis comprised of 2-3 layers of cells protected by thick cuticle layer followed by irregular 2-3 layers of hypodermal cells. 4-6 layers of cortical cells followed by endodermis, which are arranged in biconvex manner. Below the endodermis a dome shaped pericyclic region is present. Xylem vessels are smaller in size while phloem tissues are circular shaped and larger in size. Pith is in the form of compact round shaped cells (Fig. 2).

Transverse section of $C$. pendulus root showed the external cork layer comprised of 4-5 layered irregular wavy shaped cells followed by stellar region made up of cortical cells arranged in 3-4 layers. Medullary rays, thread like structures extended towards the xylem tissues. Xylem tissues are irregularly arranged. Phloem tissues are adjacent with the cortex (Fig. 3).

Modi et al. (2010); Khyade and Vaikos (2014) analyzed the histological studies of Syzygium cumini and Wrightia tinctoria respectively and stated that anatomical study is very much important for identification and diagnostic feature of the drugs. Anatomy can provide additional evidences which correspond to the anatomy for the recognition of the taxon. According to Pachkore et al. (2012) anatomical perspective of medicinal plants is an integral component of pharmacognosy.

\section{Phytochemical screening}

Qualitative Phytochemical screening: Qualitative phytochemical analysis of the stem and root extracts of $C$. pendulus showed that both the plant parts consists of many important metabolites such as fats, proteins, carbohydrates, alkaloids, tannins, saponins, steroids, flavonoids, glycosides and phenolic compounds given in (Table. 2). These phytochemical constituents have a great curative properties against different diseases.

Quantitative phytochemical screening: Quantitative phytochemical screening of the stem and root were conducted for some important phytoconstituents such as saponins, sterol, alkaloids, flavonoids and tannins. The results has been listed in (Table. 3).

Prabhu et al. (2011); Uthayakumari and Sumathy (2011); Desai et al. (2012) worked out on three Viburnum species, Jatropha maheswarii and Tinospora cordifolia respectively and revealed that active constituents such as alkaloids, flavonoids, tannins and glycosides are very important secondary metabolites which are helpful in the treatment of different disorders. Alkaloids can be use as cardiac stimulant, analgesic and as respiratory stimulant. They also possess the vasoconstriction, muscle relaxant, antispasmodic, antineoplastic, anticancer, allelopathic and insecticidal potential (Goncalves et al. 2019). The literature revealed that flavonoids possess the vasoprotective, antiinflammatory, antithrombotic, antiallergic potential, gastric mucosa protection and tumor promotion inhibition. Flavonoids also have the ability to alter immunological response, antioxidant, anticancer and antimicrobial potential (Rice et al. 1996). Tannins have antidiarrheal potential and can also be use as antidotes against heavy metals and alkaloids having poisonous effect. They also possess wound healing, antibiotic, soothing effect and various inflammatory effects. Immuno-regulation and most of the cardiac diseases can be cured by saponins and glycosides respectively (Ashok and Upadhyaya 2012). Terpenoids and saponins have the astringent properties while steroids have the potential to regulate the function of sex hormones and possessing strong pain killing potential (Al-Snafi, 2015). Phenolic compounds are valued to due to possessing antiinflammatory potential such as quercetin and antihapatotoxic potential such as silybin. Other phenolic compounds such as genistein and daidzen possessing phytoestrogenic potential and naringenin have significant insecticidal effect. They also possess antioxidant and free radical scavenger potential which can fight against cancer (Lin et al. 2016). Several researchers did the same work such as Shah and Seth (2010) analyzed Lagenaria 
siceraria and Kumar et al. (2012) carried out the phytochemical screening of Holoptelea integrifolia for phytochemicals are well in lineage with our findings and described the importance of phytochemical screening of crude drugs, which are helpful for the researchers in the field of pharmacology, phytotherapy and phytochemistry to conduct advance research on herbal plants. The present work on $C$. pendulus are helpful in exploration of the plant for further advanced research in above mentioned fields.

Powder drug study: Powder drug microscopy is an important method for the correct recognition of different cellular structures present in the powdered drug. This technique is helpful for the purity of a drug from adulterants. Powder drug analysis of stem of $C$. pendulus showed different fragments such as fibers, vessels, cortical cells, epidermal cells and pitted vessels while root showed different fragments such as cortical cells, fibers, parenchyma cells, endodermal cells, and xylem vessels (Fig. 4; Fig. 5).

Fluorescence analysis: Fluorescence analysis of stem and root powders were conducted. The powder were treated with different solvents and observed in ordinary day light and UV light (UV 254, UV 336). The results has been listed in (Table. 4). Similar studies were also conducted by other researchers like Pandya et al. (2012);
Paul et al. (2012) worked out fluorescence analysis of Cassia fistula and Mimosa pudica respectively revealed that fluorescence analysis is one of the important method for the standardization and authentication of a crude drug as this parameter is helpful in detection of important secondary metabolites which show difference in fluorescence under ordinary and UV light.

Extractive values determination: Extractive values both plant parts powder drug were determined treated with various solvents. Significant extractive values were found in methanol which were $9.32 \%$ followed by ethanol $8.15 \%$ (Table. 5). The results showed that more polar solvent (methanol and ethanol) are significant for the extraction of $C$. pendulus stem and root. Similar studies were also performed by Rani and Lakshmi (2012); Bharti and Vasudeva (2013) on Dioscorea oppositifolia and Oreganum vulgare respectively and stated that extractive value determination is helpful in the identification of a crude drug being adulterated. Various type of adulterated or exhausted drugs can detect by solvent extraction. Extraction with petroleum ether is useful for the indication of lipid contents in crude drugs. Aqueous and alcohol extraction are helpful in the indication of defective processing and adulterants in the crude drug (Kokate et al. 2008).

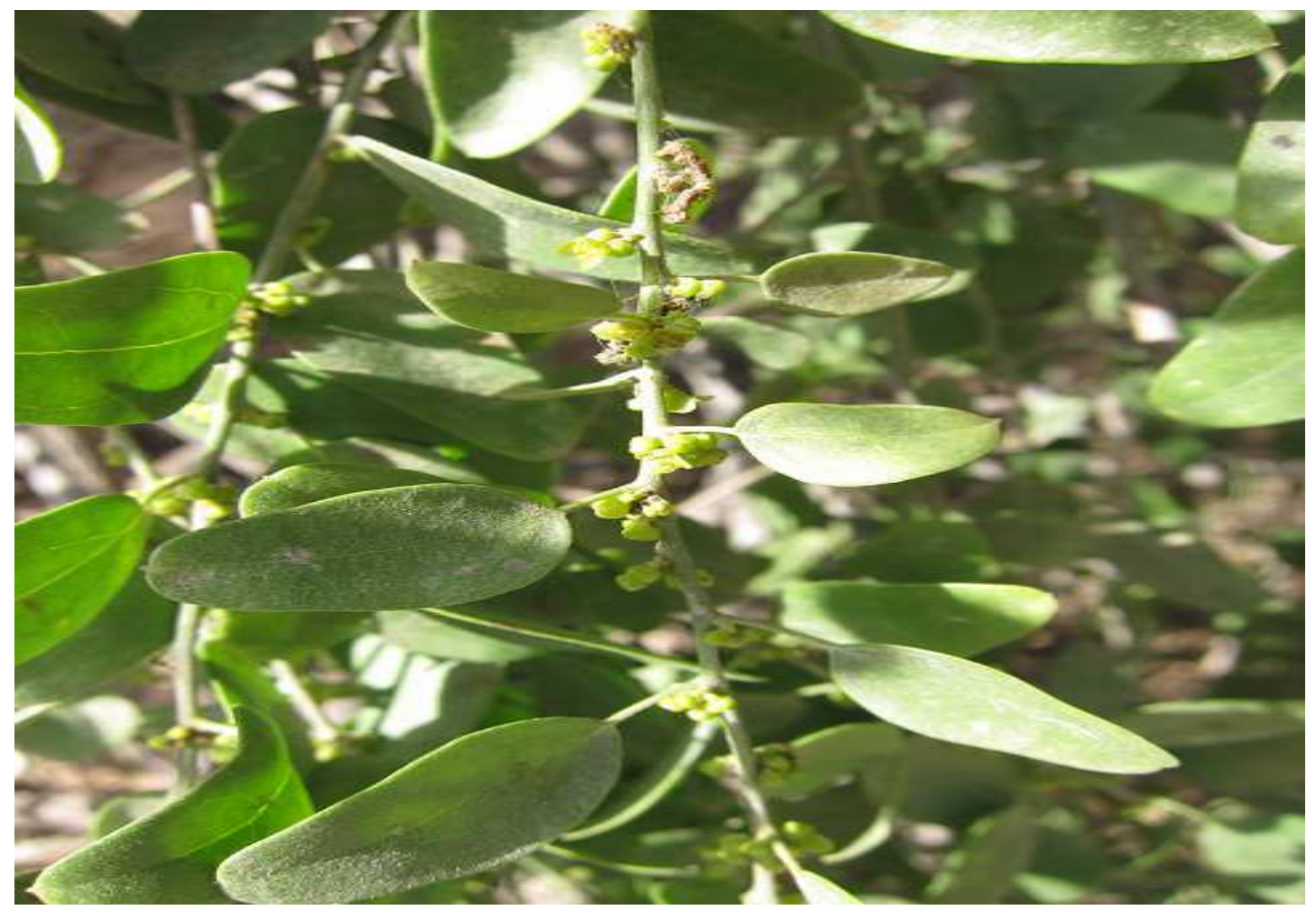

Fig. 1. Cocculus pendulus plant morphology 


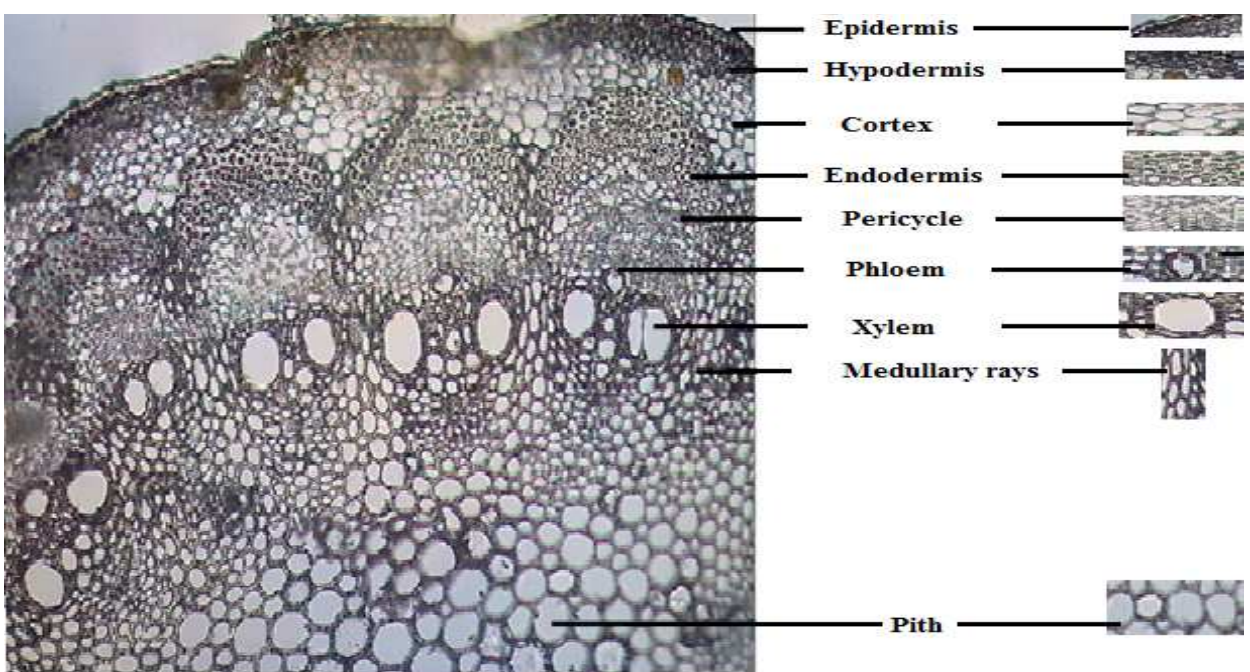

Fig. 2. Transverse section of $C$. pendulus stem.

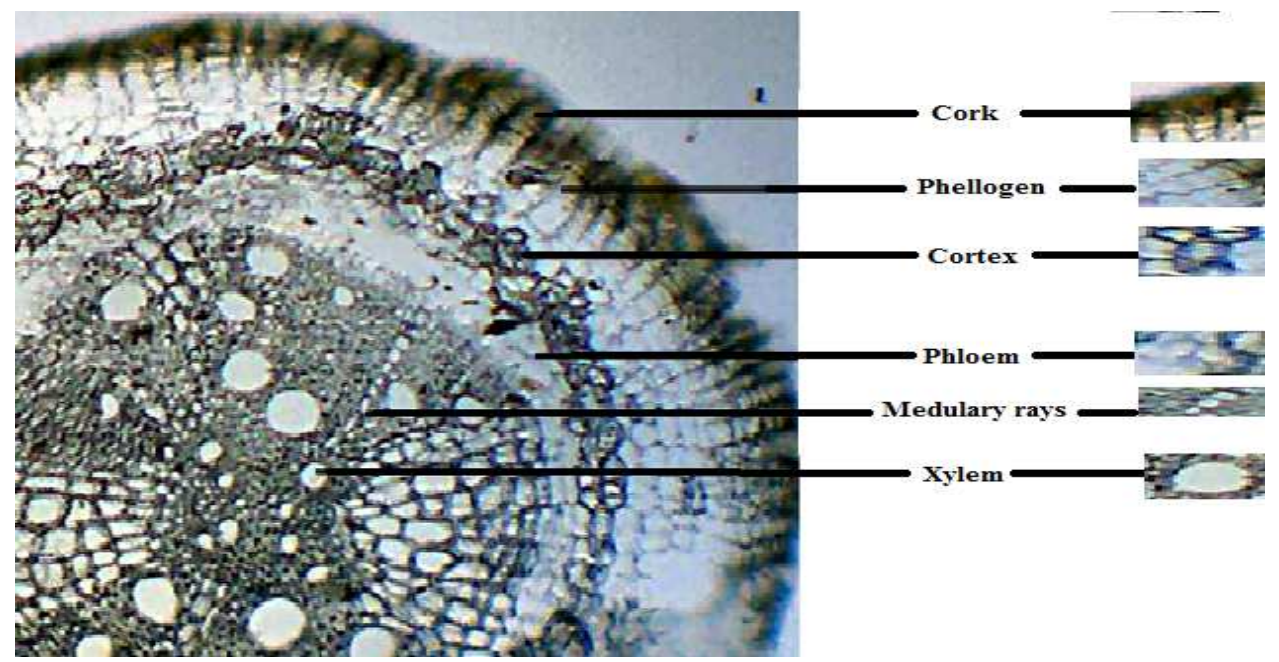

Fig. 3. Transverse section of $C$. pendulus root.

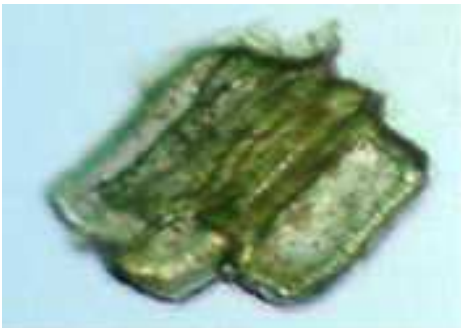

Vessels

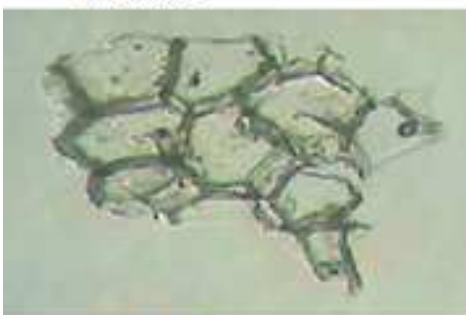

Pith

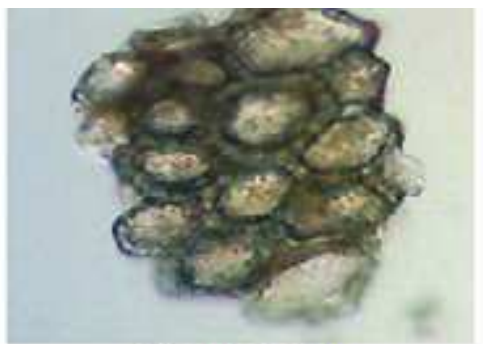

Cortical cells

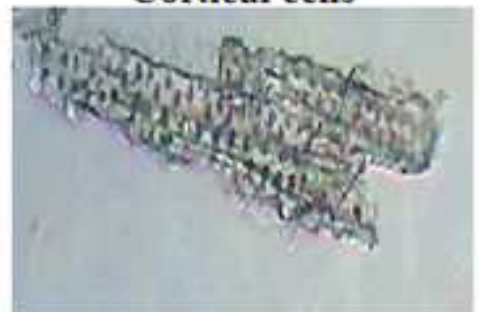

Pitted vessels

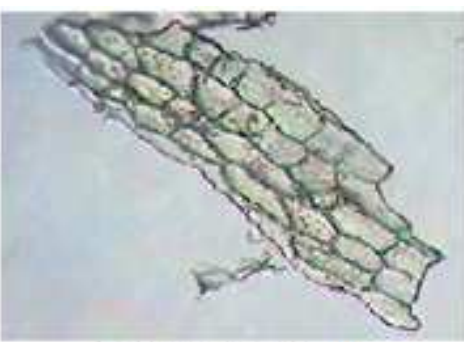

Epidermal cells

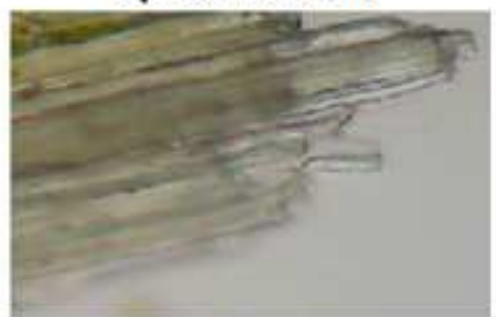

Fibers

Fig. 4. Powdered drug study of $C$. pendulus stem. 


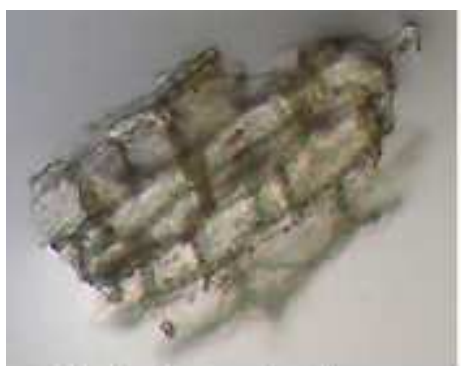

Endodermal cells

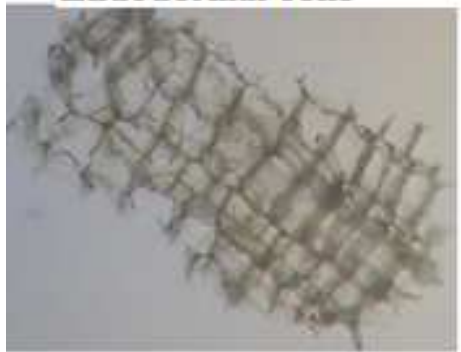

Cortical cells

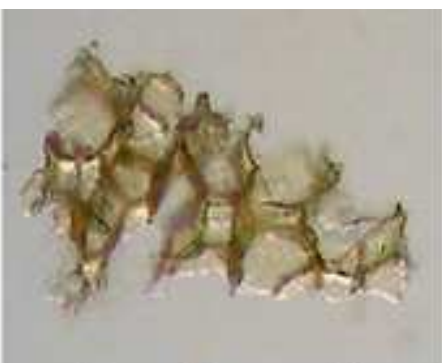

Parenchyma cells

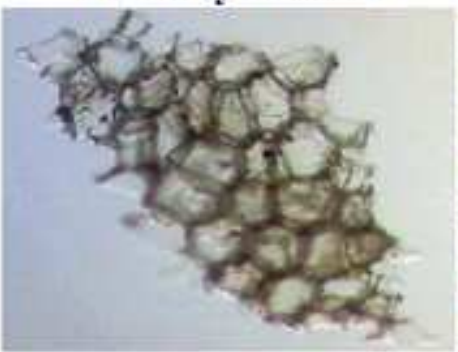

Cork cells

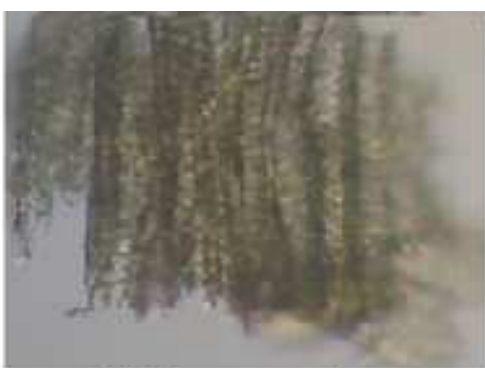

Xylem vessels

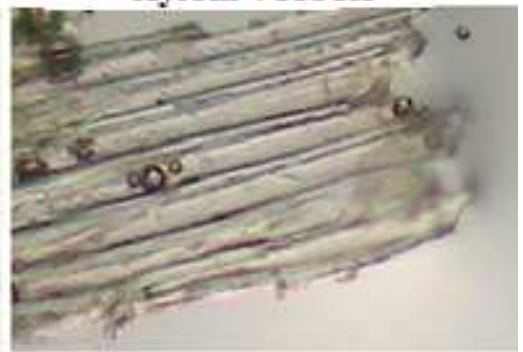

Fibers

Fig. 5. Powdered drug study of $C$. pendulus root.

Table 1. Macroscopic features of $C$. pendulus stem and root.

\begin{tabular}{cccc}
\hline S.No. & Characteristic & Stem & Root \\
\hline $\mathbf{1}$ & Shape & Cylindrical & Irregular \\
$\mathbf{2}$ & Outer surface & Light brown & Light brown \\
$\mathbf{3}$ & Inner surface & Light yellow & Light yellow \\
$\mathbf{4}$ & Odor & Characteristic & Characteristic \\
$\mathbf{5}$ & Taste & Acceptable & Slightly bitter \\
$\mathbf{6}$ & Fracture & Brittle & Brittle \\
\hline
\end{tabular}

Table 2. Phytochemical screening of the stem and root extracts of $C$. pendulus.

\begin{tabular}{ccccc}
\hline S.No. & Constituents & Test name & Stem & Root \\
\hline $\mathbf{1}$ & Carbohydrates & Molisch test & ++ & ++ \\
$\mathbf{2}$ & & Benedict's test & - & - \\
& Protein & Ninhydrine test & ++ & ++ \\
$\mathbf{3}$ & & Xanthoproteic test & ++ & ++ \\
& & Biuret test & + & + \\
& Alkaloids & Wagner's test & + & ++ \\
$\mathbf{4}$ & Phytosterol and Triterpenoids & Hager's test & + & + \\
$\mathbf{5}$ & Phenol & Dragandorrf test & ++ & ++ \\
$\mathbf{6}$ & Flavonoids & Ferric chloride test & + & ++ \\
$\mathbf{7}$ & Tannins & Alkali reagent test & ++ & + \\
$\mathbf{8}$ & Saponinss & Ferric chloride test & + & ++ \\
$\mathbf{9}$ & Glycosides & Alkali reagent test & + & + \\
$\mathbf{1 0}$ & Fixed oil and fats & Frothing test & + & + \\
$\mathbf{1 1}$ & Volatile oil & Killaer kilani test & ++ & ++ \\
\hline
\end{tabular}

Key: $++=$ Strongly detected, $+=$ Detected, $-=$ Not detected 
Table 3. Quantitative phytochemical analysis of $C$. pendulus stem and root. All values are expressed in $\mathrm{mg} / \mathrm{g}$.

\begin{tabular}{cccccc}
\hline S.No. & Part & Alkaloids & Tannins & Sterol & Saponins \\
\hline $\mathbf{1}$ & Stem & $21.47 \pm 0.54$ & $18.23 \pm 0.46$ & $71.43 \pm 1.24$ & $19.84 \pm 1.45$ \\
$\mathbf{2}$ & Root & $30.45 \pm 0.32$ & $21.43 \pm 0.96$ & $85.32 \pm 2.42$ & $28.42 \pm 0.86$ \\
\hline
\end{tabular}

Tab. 4. Fluorescence analysis of stem and root powders of $C$. pendulus.

\begin{tabular}{cllll}
\hline S.No. & \multicolumn{1}{c}{ Reagents } & \multicolumn{1}{c}{ Visible light } & \multicolumn{1}{c}{ UV 254 } & \multicolumn{1}{c}{ UV 336 } \\
\hline $\mathbf{1}$ & CS powder as such & Light yellow & Yellow & Yellow \\
$\mathbf{2}$ & CS powder+ 50\%H2SO4 & Light yellow & Brown & Green \\
$\mathbf{3}$ & CS powder+ 50\%HNO3 & Brown & Yellow & Light green \\
$\mathbf{4}$ & CS powder+ Diethyl ether & Yellow brown & Brown & Green \\
$\mathbf{5}$ & CS powder+ NaOH in H2O & Light yellow & Dark green & Bluish green \\
$\mathbf{6}$ & CS powder+ Methanol & Yellow brown & Light yellow & Yellow \\
$\mathbf{7}$ & CS powder+ Picric acid & Yellowish brown & Brown & Green \\
$\mathbf{8}$ & CS powder+ Iodine solution & Light yellow & Yellow & Yellow \\
$\mathbf{9}$ & CS powder+ NH3 solution & Light yellow & Light brown & Light yellow \\
$\mathbf{1 0}$ & CS powder+ 10\%FeCl3 & Yellow & Light yellow & Brown yellow \\
$\mathbf{1 1}$ & CR powder as such & Brown & Yellow & Greenish yellow \\
$\mathbf{1 2}$ & CR powder+ 50\%H2SO4 & Reddish brown & Brown & Dark brown \\
$\mathbf{1 3}$ & CR powder+ 50\%HNO3 & Greenish brown & Light brown & Purplish brown \\
$\mathbf{1 4}$ & CR powder+ Diethyl ether & Light brown & Yellow & Purple \\
$\mathbf{1 5}$ & CR powder+ NaOH in H2O & Brown & Green & Pinkish green \\
$\mathbf{1 6}$ & CR powder+ Methanol & Brown & Light brown & Yellow \\
$\mathbf{1 7}$ & CR powder+ Picric acid & Yellow & Brown & Yellow brown \\
$\mathbf{1 8}$ & CR powder+ Iodine solution & Yellowish brown & Brown & Green \\
$\mathbf{1 9}$ & CR powder+ NH3 solution & Dark brown & Brown & Yellow brown \\
$\mathbf{2 0}$ & CR powder+ 10\%FeCl3 & Brown & Light brown & Green \\
\hline
\end{tabular}

CS: C. pendulus stem CR: C. pendulus root

Table. 5. Extractive values of $C$. pendulus stem and root.

\begin{tabular}{ccc}
\hline Part & Solvent & Percent extracts \\
\hline & Chloroform & $1.22 \%$ \\
Stem & Methanol & $\mathbf{8 . 3 2 \%}$ \\
& Ethanol & $7.46 \%$ \\
& Petroleum ether & $0.87 \%$ \\
& n-Hexane & $0.66 \%$ \\
& Acetone & $0.55 \%$ \\
& Chloroform & $0.68 \%$ \\
& Methanol & $\mathbf{9 . 3 2 \%}$ \\
& Ethanol & $8.15 \%$ \\
& Petroleum ether & $0.66 \%$ \\
& n-Hexane & $0.53 \%$ \\
\hline
\end{tabular}

Conclusion and recommendations: Cocculus pendulus belongs to the family Menispermaceae locally known as Parwatti, is a dioecious shrubby plant. Morphological and histological features of both plant parts might be useful taxonomic information that can help the species and genera outlining. These characteristics will be more appreciated if other species of the said plant are also evaluated for the same studies. Standardization of the crude drug of both plant parts may be carried out by macroscopic examination. The phytochemical screening revealed the presence of various important phytoconstituents both qualitatively and quantitatively. Due to the presence of such important active constituents, further advance study is recommended to isolate the important secondary metabolites. 


\section{REFERENCES}

Akbar, S., U. Hanif, J. Ali, and S. Ishtiaq (2014). Pharmacognostic studies of stem, roots and leaves of Malva parviflora L. Asian Pac. J. Trop. Biomed. 4(5): 410-415.

Al-Snafi, A.E. (2015). The chemical constituents and pharmacological effects of Chenopodium album. International J. Pharmacological Screening Methods. 5(1): 10-17.

Ansari, M.M., J. Ahmad, and S.H. Ansari (2006). Pharmacognostic evaluation of the stem bark of Balanitesa egyptica. Hamdard Medicus. 50: 8294.

Ashok, P.K., and K. Upadhyaya (2012). Tannins are astringent. J. Pharmacognosy Phytochem. 1(3): 45-50.

Bharti, V. and N. Vasudeva (2013). Oreganum vulgare Linn. An Extensive Pharmacognostical and Phytochemical Quality Assessment. Adv. pharm. bull. 3(2): 277-281.

Chaffey, N.J. (2001). Putting plant anatomy in its place. Trends Plant Sci. 6: 439-440.

Dahiru, D.J., A. Onubiyi, and H.A. Umaru (2006). Phytochemical screening and antiulcerogenic effect of Moringa oleifera aqueous leaf extract. Afr. J. Tradit. Complement. Altern. Med. 3: 7075.

Desai, S., R. Metrani, S. Vantamuri, V. Ginigeri, K. Phadke, and B. Hungund (2012). Phytochemical Analysis, Antimicrobial and Antitumour Screening of Endophytes of Tinospora cordifolia. Int. J. Pharm. Bio. Sci. 3(4): 533540.

Evans, W. C. (2002). Trease and Evans pharmacognosy. 16th Ed. Saunders Elsevier Publishers; University of Nottingham (UK). $45 \mathrm{p}$

Goncalves, J., T. Rosado, S. Soares, A. Simao, D. Caramelo, A. Luis, N. Fernandez, M. Barroso, E. Gallardo, and A.P. Duarte (2019). Cannabis and Its secondary metabolites: Their use as therapeutic drugs, toxicological aspects and analytical determination. Medicines. 6(31): 147.

Harborne, J.B. (1998). Phytochemical methods. 3rd ed. Chapman and Hall (New York). 33 p

Huang, X., W. Gao, W. Zhao, T. Zhang, and J. Xu (2010). Flavone and steroid chemical constituents from rhizome of Paris axialis. Zhongguo Zhong Yao Za Zhi. 35: 2994-2998.

Khandelwal, K.R. (2004). Practical Pharmacognosy, Techniques and experiments. 12th Ed. Nirali Prakashan, Punne (India). $157 \mathrm{p}$

Khyade, M.S. and N.P. Vaikos (2014). Wrightia tinctoria a review on its ethnobotany, pharmacognosy and pharmacological profile. J. coast. life med. 2(10): 826-840.

Kim, H.K., W.K. Jeon, and B.S. Ko (2001). Flavanone glycosides from Citrus junos and their antiinfluenza virus activity. Planta Med. 67: 548549.

Kokate, C.K., A.P. Purohit, and S.B. Gokhale (2008). Textbook of Pharmacognosy. 40th ed. Nirali Ptakashan, Pune (India). $31 \mathrm{p}$

Kumar, B.J.R. and C.P. Kiladi (2009). Preliminary Phytochemical and Pharmacognostic Studies of Holoptelea integrifolia. Ethnobotanical Leaflets. 13: 1222-1231.

Kumar, D., K. Kumar, S. Kumar, T. Kumar, A. Kumar, and O. Prakash (2012). Pharmacognostic evaluation of leaf and root bark of Holoptelea integrifolia Roxb. Asian Pac. J. Trop. Biomed. 2(3): 169-175.

Lin, D., M. Xiao, J. Zhao, Z. Li, B. Xing, X. Li, M. Kong, L. Li, Q. Zhang, Y. Liu, H. Chen, W. Qin, H. Wu, and S. Chen (2016). An Overview of Plant Phenolic Compounds and their importance in Human nutrition and management of Type-2 Diabetes. Molecules. 21: 2-19.

Modi, D.C., J.K. Patel, B.N. Shah, and B.S. Nayak (2010). Pharmacognostic Studies of the seed of Syzygium cumini Linn. Int. J. of Pharma. Sci. 1(1): 20-26.

Nikam, D.D., Y.S. Jaiswal, S.S. Jirge, and Y. Chaudhar (2009). Pharmacognostic evaluation of the leaves of Sesbania sesban. J. Res. Edu. Indian Med. 25: 19-24.

Obadoni, B.O. and P.O. Ochuko (2001). Phytochemcial studies and comparative efficacy of the crude extracts of some homostatic plants in Edo and Delta States of Nigeria. Global J. Pure and Applied Sciences. 8(2): 455-459.

Pachkore, G.L., A.N. Dharasurkar, and D.A. Dhale (2012). Pharmacognostic studies of two Mentha species of Lamiaceae. Int. j. Adv. Res. pharma. bio. Sci. 2(1): 62-72.

Pandya, J.D., V.L. Patel, T.R. Desai, R.R. Lunagariya, S.D. Gajera, and A.J. Mehta (2012) . Pharmacognostic and phytochemical evaluation of leaves of Cassia fistula. Int. J. of Pharm. Life Sci. 3(2): 1424-1429.

Paul, S., D. Saha, S. Chowdhury (2012). Pharmacognostic Studies on Aerial Part of Methanolic Extract of Mimosa Pudica. Asian J. Pharmacy and Technology. 2(3): 101-103.

Prabhu, K., P.K. Karar, S. Hemalatha, and K. Ponnudurai (2011). Comparative micromorphological and phytochemical studies on the roots of three Viburnum species. Turk. J. Bot. 35: 663-670.

Rabari, H.A., S.S. Pandya, G. Vidyasagar, R. Shrinivas, B. Gajra, J.U. Somani, and R.R. Dedania (2011). 
Pharmacognostic and phytochemical investigations of Cocculus pendulus leaf. Int. J. Pharma Nanotach. 4: 1320-1330.

Rabari, H., S. Pandya, G. Vidyasagar, and B. Gajra (2010). Pharmaconostic studies of Cocculus pendulus leaf. Int. J. Pharma and Bio. Sci. 1: 113.

Rani, M.J. and K. Lakshmi (2012). Evaluation of pharmacognostical and phytochemical studies on Dioscorea oppositifolia. Int. J. of Pharmacotherapy. 2(1): 29-47.

Rao, K.N.V., S.K. Padhy, S.K. Dinakaran, D. Banji, S. Madireddy, and H. Avasarala (2010). Study of pharmacognostic, phytochemical, antimicrobial and antioxidant activities of Amaranthus tricolor linn. leaves extract. Int. J. Pharma Sci. 6: 289299.

Rice, C.A., N.J. Miller, and G. Paganga (1996). Structure-antioxidant activity relationships of flavonoids and phenolic acids. Free Radic. Biol. Med. 20: 933-956.

Shah, B.N. and A.K. Seth (2010). Screening of Lagenaria siceraria fruits for their analgesic activity. Romanian J. Biology. Plant Biology. 55: 23-26.

Upadhyay, B., K.P. Singh, and A. Kumar (2010). Pharmacognostical and antibacterial studies of different extracts of Euphorbia hirta. J. Phytol. 2: $55-60$.

Uthayakumari, F. and M. Sumathy (2011). Pharmacognostical studies on the endemic medicinal plant Jatropha maheswarii. Int. J. PharmTech Res. 3(4): 2170-2174.

Van-Buren J.P. and W.B. Robinson (1969). Formation of complexes between protein and tannic acid. J. Agr. Food Chem. 17: 772-777.

Wallis, T.E. (2009). Text book of pharmacognosy. 5th ed. CBS Publisher and Distributors; New Delhi (India). 572 p. 